\title{
Increased BMP6 Levels in the Brains of Alzheimer's Disease Patients and APP Transgenic Mice Are Accompanied by Impaired Neurogenesis
}

\author{
Leslie Crews, ${ }^{1}$ Anthony Adame, ${ }^{1}$ Christina Patrick, ${ }^{1}$ Alexandra DeLaney, ${ }^{1}$ Emiley Pham, ${ }^{1}$ Edward Rockenstein, ${ }^{1}$ \\ Lawrence Hansen, ${ }^{1,2}$ and Eliezer Masliah ${ }^{1,2}$ \\ Departments of ${ }^{1}$ Neurosciences and ${ }^{2}$ Pathology, University of California, San Diego, La Jolla, California 92093-0624
}

\begin{abstract}
During aging and in the progression of Alzheimer's disease (AD), synaptic plasticity and neuronal integrity are disturbed. In addition to the alterations in plasticity in mature neurons, the neurodegenerative process in AD has been shown to be accompanied by alterations in neurogenesis. Members of the bone morphogenetic protein (BMP) family of growth factors have been implicated as important regulators of neurogenesis and neuronal cell fate determination during development; however, their role in adult neurogenesis and in $\mathrm{AD}$ is less clear. We show here by qRT-PCR analysis that BMP6 mRNA levels were significantly increased in the hippocampus of human patients with AD and in APP transgenic mice compared to controls. Immunoblot and immunohistochemical analyses confirmed that BMP6 protein levels were increased in human AD brains and APP transgenic mouse brains compared to controls and accumulated around hippocampal plaques. The increased levels of BMP6 were accompanied by defects in hippocampal neurogenesis in AD patients and APP transgenic mice. In support of a role for BMP6 in defective neurogenesis in AD, we show in an in vitro model of adult neurogenesis that treatment with amyloid- $\beta_{1-42}$ protein $(\mathrm{A} \beta$ ) resulted in increased expression of BMP6, and that exposure to recombinant BMP6 resulted in reduced proliferation with no toxic effects. Together, these results suggest that A $\beta$-associated increases in BMP6 expression in AD may have deleterious effects on neurogenesis in the hippocampus, and therapeutic approaches could focus on normalization of BMP6 levels to protect against $\mathrm{AD}$-related neurogenic deficits.
\end{abstract}

\section{Introduction}

Alzheimer's disease (AD) is a leading cause of dementia in the aging population. Neuropathologically, AD is characterized by synaptic injury (Terry et al., 1994; Masliah et al., 1997), neuronal loss (Terry et al., 1981), and amyloid deposition (Selkoe, 1989). Although the precise mechanisms leading to neurodegeneration in $\mathrm{AD}$ remain unclear, many studies have focused on the role of amyloid- $\beta$ (A $\beta$ ) precursor protein (APP) and its products in AD pathogenesis (Selkoe, 1989, 1999).

Recent studies have revealed a dysregulation of adult neurogenesis in $\mathrm{AD}$ patients and in mouse models of the disease (Tatebayashi et al., 2003; Dong et al., 2004; Jin et al., 2004a, 2004b; Boekhoorn et al., 2006; Li et al., 2008a). Neurogenesis in the mature healthy CNS occurs in the olfactory bulb, subventricular zone, and dentate gyrus (DG) of the hippocampus, and plays a role in memory (Gage et al., 1998). There is some controversy over whether neurogenesis is increased (Jin et al., 2004b) or decreased (Boekhoorn et al., 2006; Li et al., 2008a) in AD. A recent study suggests that apparent increases in markers of neurogenesis in $\mathrm{AD}$ brains may be related to glial and vasculature-associated changes (Boek-

\footnotetext{
Received March 12, 2010; revised May 25, 2010; accepted June 16, 2010.

This work was supported by National Institutes of Health Grants AG18440, AG5131, AG022074, and AG11385.

Correspondence should be addressed to Dr. Eliezer Masliah, Department of Neurosciences, University of Califor-

nia, San Diego, La Jolla, CA 92093-0624. E-mail: emasliah@ucsd.edu.

DOI:10.1523/JNEUROSCI.1305-10.2010

Copyright $\odot 2010$ the authors $\quad 0270-6474 / 10 / 3012252-11 \$ 15.00 / 0$
}

hoorn et al., 2006; Verwer et al., 2007). A number of mouse models of AD also display reduced neurogenesis (Haughey et al., 2002a; Dong et al., 2004; Donovan et al., 2006; Rockenstein et al., 2007) [for review, see Crews et al. (2010), Demars et al. (2010), and Lazarov and Marr (2010)]. However, the molecular mechanisms involved in defective neurogenesis in $\mathrm{AD}$ and in animal models remain unclear (Diez del Corral and Storey, 2001; Rowe et al., 2007).

Bone morphogenetic proteins (BMPs) belong to the transforming growth factor- $\beta$ (TGF $\beta$ ) superfamily of cytokines, and have been implicated in embryonic (Mehler et al., 1997) and adult neurogenesis (Colak et al., 2008). However, the involvement of BMPs in neurodegenerative disorders such as AD is less well defined. A recent publication demonstrated that increased BMP4 levels correlated with reduced hippocampal cell proliferation in a mouse model of AD (Li et al., 2008b); however, whether other related proteins are affected, and whether they are dysregulated in $\mathrm{AD}$ patients, is unknown.

To investigate this possibility, we analyzed expression levels of BMP2, 6, and 7 in AD hippocampus and in APP tg mouse brains by qRT-PCR. This analysis revealed that BMP6 levels were significantly increased in the hippocampus of patients with $\mathrm{AD}$ and in the brains of APP tg mice, while levels of BMP2 and BMP7 were similar to controls. Immunoblot and immunohistochemical analyses confirmed that BMP6 protein levels were similarly increased, and that BMP6 protein accumulated surrounding diffuse and mature $A \beta$-containing plaques in the brains of $A D$ 
Table 1. Summary of clinicopathological characteristics of human cases

\begin{tabular}{|c|c|c|c|c|c|c|c|c|c|c|c|}
\hline Group & $n$ & Age (yrs) & $\begin{array}{l}\text { Gender } \\
(\mathrm{M} / \mathrm{F})\end{array}$ & $\begin{array}{l}\text { PMD } \\
\text { (h, mean) }\end{array}$ & $\begin{array}{l}\text { Duration } \\
\text { (yrs) }\end{array}$ & $\begin{array}{l}\text { Education } \\
\text { (yrs) }\end{array}$ & $\begin{array}{l}\text { Blessed score } \\
\text { (range) }\end{array}$ & DRS (mean) & $\begin{array}{l}\text { MMSE } \\
\text { (mean) }\end{array}$ & Brain weight (g) & Braak stage \\
\hline Control & 5 & $87.0 \pm 4.6$ & $2 / 3$ & $9.5 \pm 3.5$ & 0 & $13.3 \pm 2.4$ & $1-2$ & $137.3 \pm 3.45$ & $28.5 \pm 0.9$ & $1087 \pm 57.6$ & $0-1$ \\
\hline Early/moderate $A D$ & 7 & $86.1 \pm 1.7$ & $4 / 3$ & $11.8 \pm 2.8$ & $2.7 \pm 2.67$ & $13.3 \pm 1.0$ & $1-21$ & $127.3 \pm 6.3$ & $27.6 \pm 1.8$ & $1202 \pm 44.4$ & $|-| \mid$ \\
\hline Severe AD & 7 & $80.0 \pm 1.9$ & $3 / 4$ & $8.2 \pm 0.8$ & $10.2 \pm 1.4$ & $16.0 \pm 1.2$ & $16-33$ & $43.2 \pm 11.4$ & $5.8 \pm 4.2$ & $986 \pm 71.7$ & $\mathrm{VI}$ \\
\hline
\end{tabular}

PMD, Postmortem delay; yrs, years.

patients and in APP tg mice. In vitro studies in a model of adult neurogenesis showed that $\mathrm{A} \beta_{1-42}$ treatment increased BMP6 expression, and recombinant BMP6 reduced cell proliferation. Together, these results suggest that accumulation of $\mathrm{A} \beta$ during $\mathrm{AD}$ pathogenesis may upregulate BMP6 expression, and that increased levels of BMP6 in AD may have deleterious effects on adult hippocampal neurogenesis.

\section{Materials and Methods}

Specimen processing, neuropathological evaluation, and criteria for disease stage. A total of 19 human cases ( $n=5$ nondemented controls; $n=14$ $\mathrm{AD}$, of which $n=7$ early $\mathrm{AD}$ and $n=7$ severe $\mathrm{AD}$ ) were included for the present study (Table 1). Brain tissue was obtained at autopsy from patients studied at the Alzheimer Disease Research Center/University of California, San Diego (ADRC/UCSD). The last neurobehavioral evaluation was performed within 12 months before death and included Blessed score, Mini Mental State Examination (MMSE), and dementia-rating scale (DRS), and autopsies were performed within $24 \mathrm{~h}$ of death whenever possible (Table 1). Brains were processed and evaluated according to standard methods. At autopsy, brains were divided sagittally; the left hemibrain was fixed in formalin or $4 \%$ paraformaldehyde (PFA) for subsequent neuropathological and immunohistochemical analysis and the right was frozen at $-80^{\circ} \mathrm{C}$ for biochemical analyses.

Animal treatments and tissue processing. The tg mice used in this study express mutated (London V717I and Swedish K670M/N671L) human (h)APP751 under the control of the mThy-1 promoter (mThylhAPP751, line 41) (Rockenstein et al., 2001). In the hippocampus of mice from line 41, the highest hAPP levels were detected in neurons of the DG and in the CA1 region (Rockenstein et al., 2001). This tg model was selected because these mice produce high levels of $A \beta_{1-42}$, which is accompanied by a significant reduction in levels of synaptic markers by $6-9$ months of age (Rockenstein et al., 2001). Starting at 3-4 months of age, these mice display dense amyloid deposits in the frontal cortex, and by $5-7$ months of age, increased size (average diameter of $25-30 \mu \mathrm{m}$ ) and numbers of plaques in the frontal cortex are detected, and dense amyloid deposits are also observed in the subiculum of the hippocampus, thalamus, and olfactory region (Rockenstein et al., 2001). The increase in plaque numbers observed at 5-7 months of age was associated with a progressive increase in levels of $\mathrm{A} \beta_{1-42}$, which measured $\sim 2-3 \mu \mathrm{g} / \mathrm{g}$ by ELISA at this age (Rockenstein et al., 2001). Moreover, at 6 months of age, APP tg mice showed significant performance deficits not related to motor impairments compared to non-tg mice in the spatial learning portion of the water maze test (Rockenstein et al., 2003). In sum, these animals exhibit behavioral deficits, synaptic damage, and plaque formation at an early age (beginning at 3 months) (Rockenstein et al., 2001, 2002). Transgenic lines were maintained by crossing heterozygous tg mice with non-tg C57BL/6 $\times$ DBA/2 F1 breeders. All mice were heterozygous with respect to the transgene and the non-tg littermates served as controls.

For measurements of BMP6 expression levels, mice ( $n=4$ non-tg, one female, three males; $n=4$ APP tg, three females, one male) were maintained until 6 months of age, followed by biochemical and neuropathological studies. For studies of neurogenesis, 6 -month old mice $(n=4$ non-tg; $n=4$ APP $\operatorname{tg}$ ) received five injections (one per day) with 5-bromo-2-deoxyuridine (BrdU, Sigma-Aldrich) at $50 \mathrm{mg} / \mathrm{kg}$. After 1 month, mice were killed for analysis of levels of BMP expression and markers of neurogenesis. All experiments described were approved by the animal subjects committee at UCSD and were performed according to National Institutes of Health (NIH) recommendations for animal use.
Table 2. Oligonucleotide sequences used as primers for qRT-PCR in human and mouse brains, and rat NPCs

\begin{tabular}{llll}
\hline Gene ID & Accession & Primer F $\left(5^{\prime} \rightarrow 3^{\prime}\right)$ & Primer $\mathrm{R}\left(5^{\prime} \rightarrow 3^{\prime}\right)$ \\
\hline BMP2 (human) & NM 001200 & GCCCTCATCAAGGGTGGAA & TGCGTGTTGGGCAAAAAGTT \\
BMP2 (rat) & NM 017178 & ATGCTGTGTCCCCACTGAGC & GCAACCCTCCACAACCATGT \\
BMP6 (human) & NM 001718 & CGTGAAGGCAATGCTCACCT & CCTGTGGCGTGGTATGCTGT \\
BMP6 (rat) & NM 013107.1 & GCACACATGAATGCCACCAA & CAGCATGGTTGGGGACGTA \\
BMP6 (murine) & NM 007556 & AAGACCCGGGGTGGCTCTA & CTGTGTGAGCTGCCTTGCT \\
BMP7 (human) & NM 001719.2 & CAAGCTGTGCAGGCAAAACC & TGGCTGGTAGGCGCTCATAA \\
BMP7 (rat) & XM 342591 & TCTCTCACTGCCCACCTTGG & CCACGGTGTGCTCAGGTTC \\
$\beta$-Actin (human) & NM 001101.3 & ACGGTGAAGGTGACAGCAGTCG & AATGTGCAATCAAAGCCTCGGC \\
$\beta$-Actin (murine) & NM 007393 & CCGTGAAAAGATGACCCAGA & AGGCATACAGGGACAGCACA \\
HPRT (rat) & NM 012583 & GACAGCGGCAAGTTGAATCTACA & CAAAAGGGACGCAGCAACAG \\
\hline & & &
\end{tabular}

In accordance with NIH guidelines for the humane treatment of animals, mice were anesthetized with chloral hydrate and flush perfused transcardially with $0.9 \%$ saline to preserve one hemibrain for biochemical analysis and the other for fixation and subsequent immunohistochemical analysis. Brains were removed and divided sagittally. One hemibrain was postfixed in phosphate-buffered $4 \% \mathrm{PFA}$ at $4^{\circ} \mathrm{C}$ for $48 \mathrm{~h}$ and sectioned at $40 \mu \mathrm{m}$ with a Vibratome 2000 , while the other hemibrain was snap frozen and stored at $-70^{\circ} \mathrm{C}$ for biochemical analyses.

$q R T-P C R$ and immunoblot analyses. For qRT-PCR of brain tissue, mRNA was extracted from frozen samples from the hippocampus of human brains ( $n=5$ nondemented controls; $n=7$ early $\mathrm{AD}$ and $n=7$ severe $\mathrm{AD}$ ) or mouse brains ( $n=4$ non-tg; $n=4$ APP tg) using TriReagent (Molecular Research Center) according to the manufacturer's protocols. For qRTPCR of cultured neuronal progenitor cells (NPCs), cells were lysed and RNA was purified using the RNeasy kit (Qiagen). Two micrograms of total RNA from each sample was reverse transcribed using the iScript cDNA Supermix Synthesis kit (Bio-Rad) in accordance with the manufacturer's instructions. Primer sequences used are detailed in Table 2. For brain tissue samples, actin was used as a reference gene, and for NPCs, hypoxanthine-guanine phosphoribosyltransferase (HPRT) was used as a reference gene due to the relatively low baseline levels of BMP6 in these cells. The HPRT gene is reported as a constitutively expressed housekeeping gene with low mRNA levels, which makes it suitable as an endogenous mRNA control in RT-PCR for highly sensitive quantification of low copy mRNAs (Pernas-Alonso et al., 1999). Quantitative RT-PCR was performed using the iCycler iQ Real-Time PCR Detection System (Bio-Rad). Reactions were performed in a volume of $25 \mu \mathrm{l}$ using the iQ SYBR Green Supermix (Bio-Rad) according to the manufacturer's instructions.

For immunoblot analysis of samples from human or mouse brains, briefly as previously described (Cole et al., 1988; Masliah et al., 2000), $0.1 \mathrm{~g}$ of frozen tissue was homogenized in $500 \mu \mathrm{l}$ of a detergent-free HEPES-based lysis buffer (1.0 mM HEPES, $5.0 \mathrm{~mm}$ benzamidine, $2.0 \mathrm{~mm}$ 2-mercaptoethanol, $3.0 \mathrm{~mm}$ EDTA, $0.5 \mathrm{~mm}$ magnesium sulfate, $0.05 \%$ sodium azide; final $\mathrm{pH} 8.8$ ) that facilitates separation of membrane and cytosolic fractions. Fresh protease and phosphatase inhibitor cocktails (Calbiochem) were added to all lysis buffers. Following a brief centrifugation step to clear nuclei and cell debris, total homogenates were then centrifuged for $1 \mathrm{~h}$ at $100,000 \mathrm{rpm}$ at $4^{\circ} \mathrm{C}$. Supernatants were saved (cytosolic fraction) and the pellets (membrane fraction) were resuspended in $500 \mu \mathrm{l}$ of HEPES lysis buffer. For immunoblot analysis of cell homogenates, adherent cells in culture were lysed in buffer composed of $10 \mathrm{~mm}$ Tris-HCl, pH 7.4, $150 \mathrm{~mm} \mathrm{NaCl}, 5 \mathrm{~mm}$ EDTA (TNE) containing 1\% Triton X-100 to obtain total cell lysates. For immunoblot analysis, cytosolic and membrane fractions from brain homogenates or total cell ly- 
sates were separated by gel electrophoresis on $4-12 \%$ Bis-Tris gels (Invitrogen) and blotted onto $0.45 \mu \mathrm{m}$ PVDF membranes (Millipore). Immunoblots were probed with antibodies against secreted BMP6 (mouse monoclonal, RnD Systems) or BMP6 precursor (mouse monoclonal, Morph 6.1 clone, Millipore; or rabbit polyclonal, Abgent), A $\beta$ (82E1 clone, specific for a $1-16$ of $\mathrm{A} \beta, \mathrm{IBL}$ ), or actin (Millipore) as a loading control as previously described (Rockenstein et al., 2001). Blots were imaged and analyzed with the VersaDoc gel imaging system and Quantity One software (Bio-Rad).

Immunohistochemical analysis. For analysis of levels of BMP6 and markers of neurogenesis in the hippocampus or cortex of AD patients and APP tg mice, brain sections were immunolabeled with the antibodies against BMP6 (mouse monoclonal from Millipore, or rabbit polyclonal from Abgent), doublecortin (DCX, marker of migrating neuroblasts, goat polyclonal, Santa Cruz Biotechnology), sex-determining region Y-box 2 (SOX2, marker of undifferentiated NPCs, mouse monoclonal), or BrdU (marker of proliferating cells labeled with BrdU, rat monoclonal, AbD Serotec). BMP6 (1:500) and SOX2 (1:500) antibodies were detected with the Tyramide Signal Amplification-Direct (Red) system (NEN Life Sciences). DCX (1:50) and BrdU (1:100) antibodies were detected with fluorescein isothiocyanate (FITC)-conjugated secondary antibodies (1:75, Vector Laboratories). A subset of sections immunolabeled with the monoclonal BMP6 antibody (1:500, Millipore) were colabeled with the mouse monoclonal antibody against $\mathrm{A} \beta$ (clone 6E10, 1:500, Signet Laboratories) or DCX (1:50, Santa Cruz) detected with FITCconjugated secondary antibodies (1:75, Vector Laboratories).

Sections were mounted under glass coverslips with ProLong Gold antifade reagent with DAPI (Invitrogen) and imaged with a Zeiss $63 \times$ (N.A. 1.4) objective on an Axiovert 35 microscope (Zeiss) with an attached MRC1024 laser scanning confocal microscope system (Bio-Rad) (Masliah et al., 2000). All sections were processed simultaneously under the same conditions and the experiments were performed twice to assess reproducibility. To confirm the specificity of primary antibodies, control experiments were performed where sections were incubated overnight in the absence of primary antibody (deleted) or primary antibody preincubated with blocking peptide.

For all immunolabeling studies, assessment of levels of immunoreactivity was performed using the Image-Pro Plus program (Media Cybernetics). For each case or mouse a total of three sections (10 images per section) were analyzed to estimate the average number of immunolabeled cells per unit area $\left(\mathrm{mm}^{2}\right)$ or the average intensity of the immunoreactive signal (corrected pixel intensity).

Quantitative analysis of neurogenesis in the hippocampus. For this purpose, a systematic, random counting procedure, similar to the optical disector (Gundersen et al., 1988), was used as described previously (Williams and Rakic, 1988; Rockenstein et al., 2007). For the purpose of the present study the morphometric analysis was focused on the subgranular zone (SGZ) of the DG. This area corresponds to the layer of NPCs located directly under the first layer of mature granular cells in the DG, which in addition to the SGZ, includes the granular cell layer (GCL) and the molecular layer (ML). The analysis was centered on the SGZ because a previous study has shown that this is the area most consistently affected in APP tg mice (Donovan et al., 2006). To determine the number of BrdU+ or DCX + cells in the SGZ of the hippocampus, every sixth section $(200 \mu \mathrm{m}$ interval) of the left hemisphere was selected from each animal and processed for immunohistochemistry. The reference volume was determined by tracing the areas using a semiautomatic stereology system (Stereoinvestigator, MicroBrightField). Positive cells were counted within a $60 \times 60 \mu \mathrm{m}$ counting frame, which was spaced in a $300 \times 300 \mu \mathrm{m}$ counting grid. Positive profiles that intersected the uppermost focal plane (exclusion plane) or the lateral exclusion boundaries of the counting frame were not counted. The total counts of positive profiles were multiplied by the ratio of reference volume to sampling volume to obtain the estimated number of positive cells for each structure. Results were expressed as fold change compared to controls so that the scale is comparable in the studies of neurogenesis in both human and mouse brains.

NPC culture and neuronal differentiation assay. Adult rat hippocampal NPCs (generously provided by F. Gage, Salk Institute, La Jolla, CA) were cultured routinely for expansion essentially as previously described (Ray and Gage, 2006) with some modifications. Briefly, cells were grown for expansion in DMEM/F12 media (Mediatech) containing B27 supplement, $1 \times$ L-glutamine, and $1 \times$ antibiotic-antimycotic (all from Invitrogen). For induction of neuronal differentiation, cells were plated onto poly-ornithine/laminin (Sigma-Aldrich)-coated plates or coverslips and transferred the next day to differentiation media containing N2 supplement (Invitrogen), $1 \mu \mathrm{M}$ all-trans retinoic acid (Sigma-Aldrich), $5 \mu \mathrm{M}$ forskolin (Sigma-Aldrich), and 1\% FBS. Cells were differentiated for $4 \mathrm{~d}$, and fresh differentiation media was added at day 2 .

In vitro cell treatments and proliferation, viability, and toxicity assays. For determination of the effects of $A \beta$ exposure on BMP6 expression levels, cultured NPCs were treated with recombinant A $\beta$. Adult rat hippocampal NPCs were plated for differentiation and cultures were exposed on day 3 of differentiation ( $24 \mathrm{~h}$ incubation) with freshly solubilized $\mathrm{A} \beta_{1-42}(1 \mu \mathrm{M}$, American Peptide). This concentration of $\mathrm{A} \beta$ was selected because it was determined to be sublethal in this cell type and is within the range of $\mathrm{A} \beta$ concentrations used in previous in vitro studies investigating the effects of $A \beta$ on neurogenesis (Haughey et al., 2002a; Haughey et al., 2002b). Cells were harvested on day 4 by cell lysis and total protein or RNA was harvested and prepared for immunoblot or qRTPCR analyses, respectively.

For determination of the effects of BMP6 on cell proliferation, viability, and toxicity, NPCs were exposed to recombinant BMP6 (50-100 $\mathrm{ng} / \mathrm{ml}$, BioVision) throughout the duration of in vitro differentiation (4 d). Media was changed and fresh recombinant BMP6 added at day 2 of differentiation. A subset of samples were treated with BrdU for $24 \mathrm{~h}$ before the differentiation endpoint and analyzed using a Cell Proliferation Assay kit (Calbiochem) according to the manufacturer's instructions. Additional experiments were performed to assess potential toxicity of BMP6 treatment using the CellTiter MTT-based Viability Assay (Promega) and the LDH-based CytoTox Assay (Promega).

Statistical analysis. All experiments were performed blind coded and in triplicate. Values in the figures are expressed as means \pm SEM. To determine the statistical significance, values were analyzed by one-way ANOVA with post hoc Dunnett's test when comparing differences between nondemented controls and $\mathrm{AD}$ cases or in vitro cell treatment groups, or by Student's $t$ test when comparing differences between non-tg control mice and APP tg animals. The differences were considered to be significant if $p$ values were $<0.05$.

\section{Results}

\section{BMP6 levels are elevated in the dentate gyrus of $A D$ patients and accumulate around plaques in the hippocampus}

To determine novel candidate regulators of neurogenesis in $\mathrm{AD}$, we screened gene array studies of neurogenesis in the aging hippocampus (Diez del Corral and Storey, 2001; Rowe et al., 2007). A comparison of these results revealed that the BMP family of proteins was disproportionately represented; specifically, BMP2, 6, and 7 were dysregulated in the aged hippocampus. To examine the expression levels of these BMPs in the brains of human AD patients, samples from the hippocampus were homogenized and processed for qRT-PCR and immunoblot analyses. First, to screen mRNA levels of these BMPs, qRT-PCR analysis was performed with primers specific for BMP2, BMP6, BMP7, and actin as a reference gene (Table 2, Fig. $1 A-C$ ). This analysis showed that of the three BMPs measured, only BMP6 mRNA levels (Fig. 1B) were significantly increased in the brains of patients with early and severe AD compared to nondemented controls. BMP2 and BMP7 levels were similar among all three groups (Fig. 1A,C). Because of the significant, and trending toward a stagedependent, increase in BMP6 mRNA levels in patients with AD, we selected this protein for further analysis of expression levels by immunohistochemistry and immunoblot.

To characterize the patterns of upregulation of BMP6 expression in the brains of $A D$ patients, immunohistochemical analysis 
A

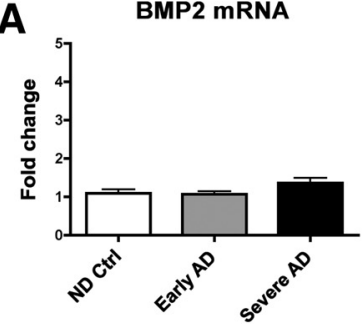

ND ctrl
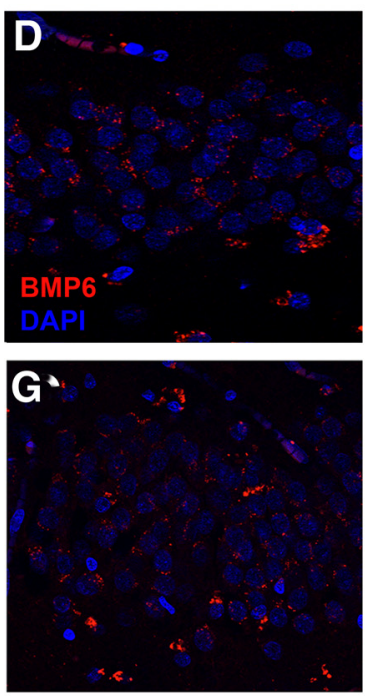

J

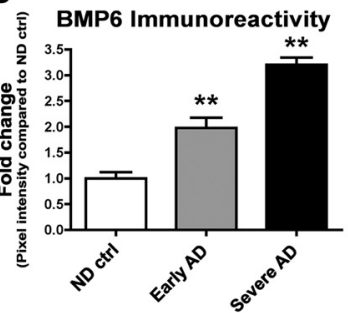

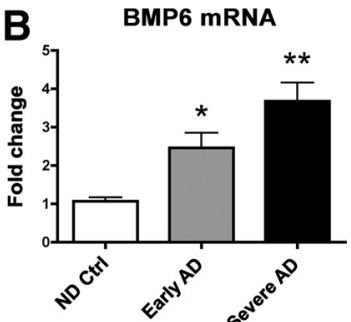

Early AD
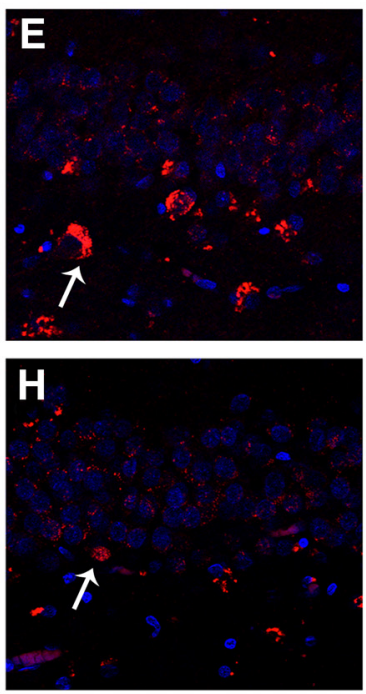

K

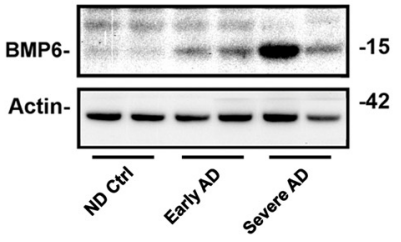

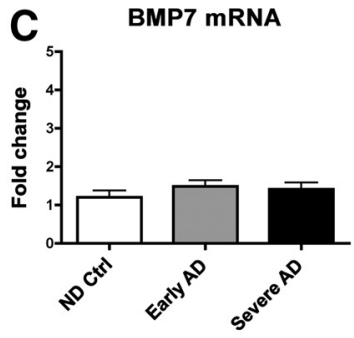

Severe AD
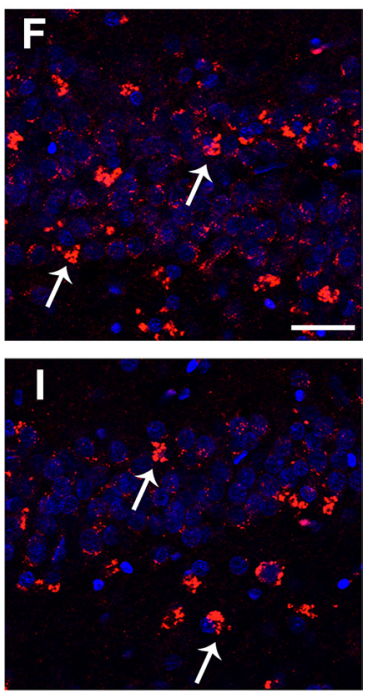

$\mathbf{L}$

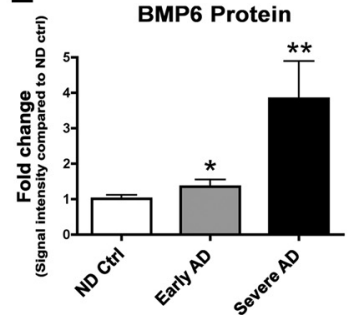

Figure 1. $\quad$ qRT-PCR, immunohistochemical, and immunoblot analyses of BMP levels in the hippocampus of AD patients. To screen for changes in BMP expression levels in AD brains, mRNA was extracted from the hippocampus of age-matched nondemented control (ND ctrl) and AD brains and prepared for qRT-PCR analysis. $\boldsymbol{A}-\boldsymbol{C}$, Levels of BMP2 (A), BMP6 (B), and BMP7 (C) mRNA were measured and corrected for $\beta$-actin levels as a control. Of the three BMPs studied, only levels of BMP6 mRNA $(\boldsymbol{B})$ were significantly increased in the brains of AD patients compared to nondemented control cases. For immunohistochemical analysis, D-F depict representative immunolabeling with a mouse monoclonal antibody against BMP6 (Millipore), and G-I show representative immunolabeling with a rabbit polyclonal antibody against BMP6 (Abgent). All images are from the dentate gyrus, and sections were costained with DAPI (blue) to label cell nuclei. Scale bar, $40 \mu \mathrm{m}$ for all images. $\boldsymbol{D}-\boldsymbol{F}$, Immunohistochemical analysis with a monoclonal antibody against BMP6 (detected with Tyramide Red) showed that BMP6 immunoreactivity (arrows, $\boldsymbol{E}, \boldsymbol{F}$ ) increased in the hippocampus of AD brains compared to nondemented controls. In severe AD cases, BMP6-immunoreactive cells (arrows, $\boldsymbol{F}$ ) were detected in both the subgranular zone and the granular cell layer. $\mathbf{G}-\mathbf{I}$, Immunohistochemical analysis with a polyclonal antibody against BMP6 (detected with Tyramide Red) showed a similar pattern of BMP6 immunoreactivity (arrows, $\boldsymbol{H}$, I). J, Semiquantitative analysis of levels of BMP6 immunoreactivity by immunohistochemistry with the Millipore antibody confirmed that BMP6 protein levels were increased in the hippocampus of AD brains compared to controls. $\boldsymbol{K}$, Representative immunoblot analysis with the Millipore antibody showing increased expression of the mature form of BMP6 (15 kDa band) in homogenates from the hippocampus of AD patients compared to nondemented controls. $L$, Semiquantitative analysis of levels of BMP6 as measured by immunoblot in hippocampal brain homogenates confirmed increased BMP6 immunoreactivity in the hippocampus of AD patients compared to controls ( $n=5$ nondemented control cases, $n=7$ early AD, and $n=7$ severe AD cases analyzed, ${ }^{*} p<0.05$ and ${ }^{* *} p<0.01$ compared to nondemented controls by one-way ANOVA with post hoc Dunnett's test).

was performed. For this purpose, sections from human brains were immunolabeled with monoclonal or polyclonal antibodies against BMP6 (Fig. $1 D-I$ ). To verify the specificity of these antibodies in human brain tissue, control experiments were performed without primary antibody or with the antibody preadsorbed with blocking peptide (supplemental Fig. $1 A-D$, avail- able at www.jneurosci.org as supplemental material). Incubation of sections with no primary antibody (supplemental Fig. $1 A$, available at www.jneurosci.org as supplemental material), or with primary polyclonal antibody preincubated with blocking peptide (supplemental Fig. $1 B$, available at www.jneurosci.org as supplemental material), abolished the signal detected in hippocampal sections from the brain of an $\mathrm{AD}$ patient. Similar patterns of immunoreactivity were observed with both a polyclonal (supplemental Fig. 1C, available at www. jneurosci.org as supplemental material) and monoclonal (supplemental Fig. 1D, available at www.jneurosci.org as supplemental material) antibody against BMP6.

In human brain sections from the hippocampus, BMP6 expression was detected in the cytoplasm of cells in the DG, and increased immunoreactivity with the BMP6 monoclonal antibody was observed in sections from patients with early or severe AD compared to nondemented controls (Fig. $1 D-F$ ). In severe $\mathrm{AD}$ cases, distinct BMP6-immunoreactive cells were detected in both the SGZ and the GCL. Immunolabeling with a polyclonal antibody against BMP6 (Fig. 1G-I) showed a similar pattern of immunoreactivity and increased levels of BMP6 in AD cases. Semiquantitative image analysis of BMP6 immunoreactivity with the monoclonal antibody showed significantly increased levels of BMP6 protein in the hippocampus of $\mathrm{AD}$ patients compared to nondemented controls (Fig. 1J). Moreover, increased levels of BMP6 corresponded with increased severity of disease in patients with early and severe AD (Fig. $1 J$ ). Immunoblot analysis confirmed that levels of BMP6 were significantly increased in the hippocampus of AD patients compared to controls (Fig. $1 K, L$ ). BMP6 in human brain tissues was detected as a doublet with two bands present ranging from 15 to $23 \mathrm{kDa}$. We confirmed by additional control experiments that the lower band corresponded with the molecular weight of a prominent immunoreactive band detected in positive control 293T cells expressing a plasmid encoding for human BMP6 (data not shown). The weaker upper band identified on the Western blots of human brain samples might represent a glycosylated, or other posttranslationally modified, form of BMP6, as suggested by recent studies (Saremba et al., 2008; Arndt et al., 2010). It is possible that a fraction of the increase in the lower BMP6-immunoreactive band could be due to a shift in the proportion of the protein that is glycosylated; however, the similarly elevated levels of BMP6 mRNA suggest that the increased protein levels are due primarily to upregulation of transcription. 
To determine whether increased BMP6 levels in AD might be related to any pathological features of the disease, we assessed the localization of BMP6 immunoreactivity in relation to $\mathrm{A} \beta$-containing plaques in hippocampal sections from the brains of $\mathrm{AD}$ patients (Fig. $2 A-F$ ). Interestingly, double-immunohistochemical analysis with a monoclonal antibody against BMP6 and an antibody against $\mathrm{A} \beta$ (6E10) showed a striking halo-like pattern of BMP6 immunoreactivity surrounding both some diffuse (Fig. $2 A-C$ ) and most mature (Fig. $2 D-F$ ) plaques located in the molecular and pyramidal layers of the hippocampus. Interestingly, analysis of the frequency of these BMP6 "halos" showed that a majority of mature plaques $(\sim 72.5 \%)$ were surrounded by a ring-like pattern of BMP6 immunoreactivity, while only a small fraction of diffuse plaques $(\sim 8.5 \%)$ displayed associated BMP6 immunoreactivity.

To assess whether the alterations in BMP6 expression levels were specific to the human hippocampus, or whether this effect could be detected in other nonneurogenic regions of the brain such as the cortex, immunohistochemical analysis was performed with samples from the cortex (layer V) of patients with $\mathrm{AD}$ and nondemented controls. Similar to the upregulation of BMP6 expression detected in the hippocampus, immunolabeling studies with the monoclonal antibody against BMP6 showed increased BMP6 immunoreactivity in the cortex of $\mathrm{AD}$ patients compared to controls (supplemental Fig. 2A-C, available at www.jneurosci. org as supplemental material). Together, these results suggest that BMP6 levels may be increased across multiple brain regions in patients with $\mathrm{AD}$.

Increased hippocampal BMP6 expression is accompanied by reduced markers of neurogenesis in $\mathrm{AD}$

Given that BMPs have been shown to play an important role in embryonic neurogenesis (Mehler et al., 1997), it is possible that the increased hippocampal expression levels of the secreted protein BMP6 might directly target NPCs in this region. To determine whether increased BMP6 expression levels in AD brains might be accompanied by alterations in markers of neurogenesis, sections from the hippocampus of $\mathrm{AD}$ patients and nondemented controls were analyzed by immunohistochemistry with antibodies against the neuroblast marker DCX and the early NPC marker SOX2 (Fig. 3). Image analysis showed that the numbers of DCX-positive cells (Fig. $3 A-C$ ) and levels of SOX2 immunoreactivity (Fig. 3D-F) were significantly reduced in the $\mathrm{DG}$ of $\mathrm{AD}$ hippocampus compared to nondemented control cases. In support of a role for increased BMP6 expression in defective neurogenesis in $\mathrm{AD}$, double-immunohistochemical analysis of sections from the hippocampus of an $\mathrm{AD}$ patient showed that BMP6 immunoreactivity was detected in close proximity to, and within, some neurogenic DCX-positive cells in the SGZ (supplemental Fig. 3A-C, available at www.jneurosci.org as supplemental
BMP6
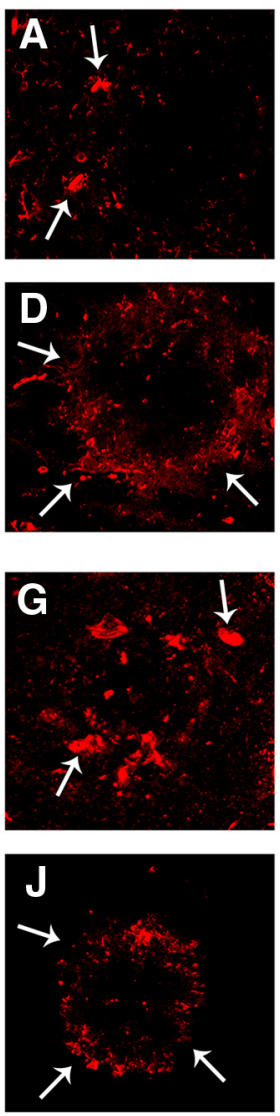

$\mathrm{A} \beta(6 \mathrm{E} 10)$
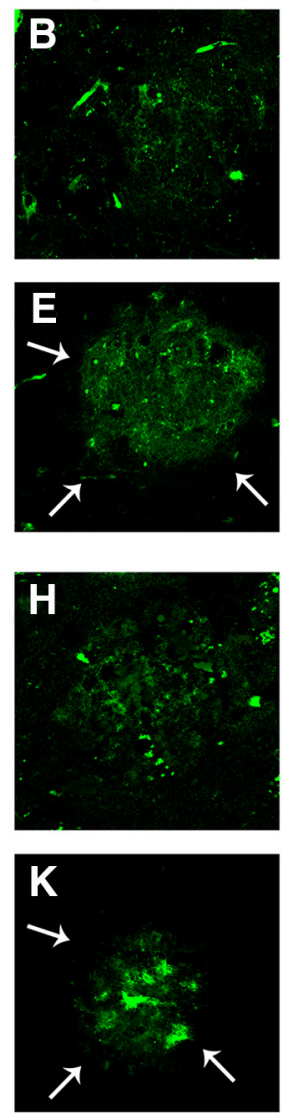

merged
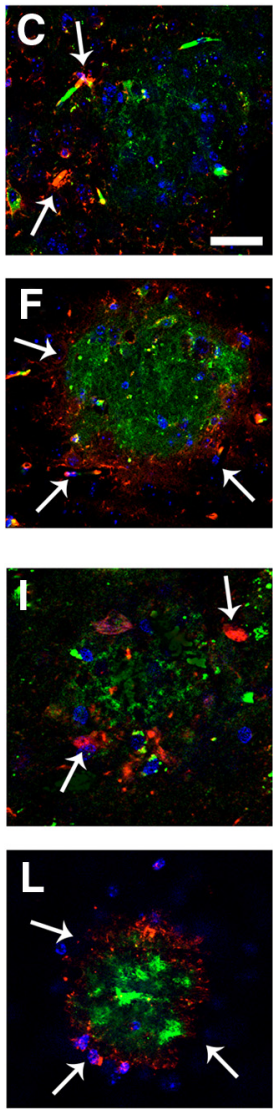

Figure 2. BMP6 immunoreactivity surrounds plaques in the hippocampus of AD patients and APP tg mice. Sections from the brains of severe AD cases or APP tg mice were immunolabeled with the monoclonal antibody against BMP6 (Millipore) detected with Tyramide Red and colabeled with an antibody against $A \beta$ (6E10, Signet) detected with a FITC-tagged secondary antibody. All

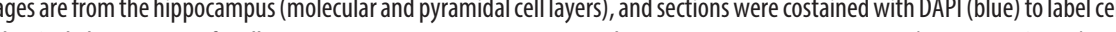
case with severe AD. $\mathbf{G}-\boldsymbol{L}$, Representative images showing BMP6 immunoreactivity (arrows, $\mathbf{G}, \boldsymbol{I}, \boldsymbol{J}, \boldsymbol{L}$ ) surrounding $A \beta$ immunoreactive diffuse $(\mathbf{G}-\boldsymbol{I}$ ) and mature $(\boldsymbol{J}-\boldsymbol{L})$ plaques (arrows, $\boldsymbol{K}, \boldsymbol{L}$ ) in the brain of an APP $\operatorname{tg}$ mouse.

material). Together, these results suggest that the impaired neurogenesis observed in the hippocampus of $\mathrm{AD}$ patients may be related to elevated levels of BMP6.

Increased BMP6 expression in the dentate gyrus of APP tg mice is accompanied by reduced hippocampal neurogenesis To begin to understand the mechanisms involved in $\mathrm{AD}$ associated elevation of BMP6 expression, protein and mRNA levels were measured in the brains of mice that express high levels of the human form of the A $\beta$ precursor, APP. Similar to the results obtained in the brains of AD patients, $\mathrm{qRT}$-PCR analysis showed that BMP6 mRNA levels were significantly increased in the brains of APP tg mice compared to non-tg controls, but levels of BMP2 and BMP7 were unchanged (Fig. $4 A$ ). To assess protein levels of BMP6, immunohistochemical analysis was then performed with monoclonal or polyclonal antibodies against BMP6 (Fig. $4 B-E$ ). To verify the specificity of these antibodies in mouse brain tissue, control experiments were performed without primary antibody or with the antibody preadsorbed with blocking peptide (supplemental Fig. $1 E-H$, available at www.jneurosci.org as supplemental material). Incubation of brain sections with no primary antibody (supplemental Fig. $1 E$, available at www. jneurosci.org as supplemental material) or with primary anti- 

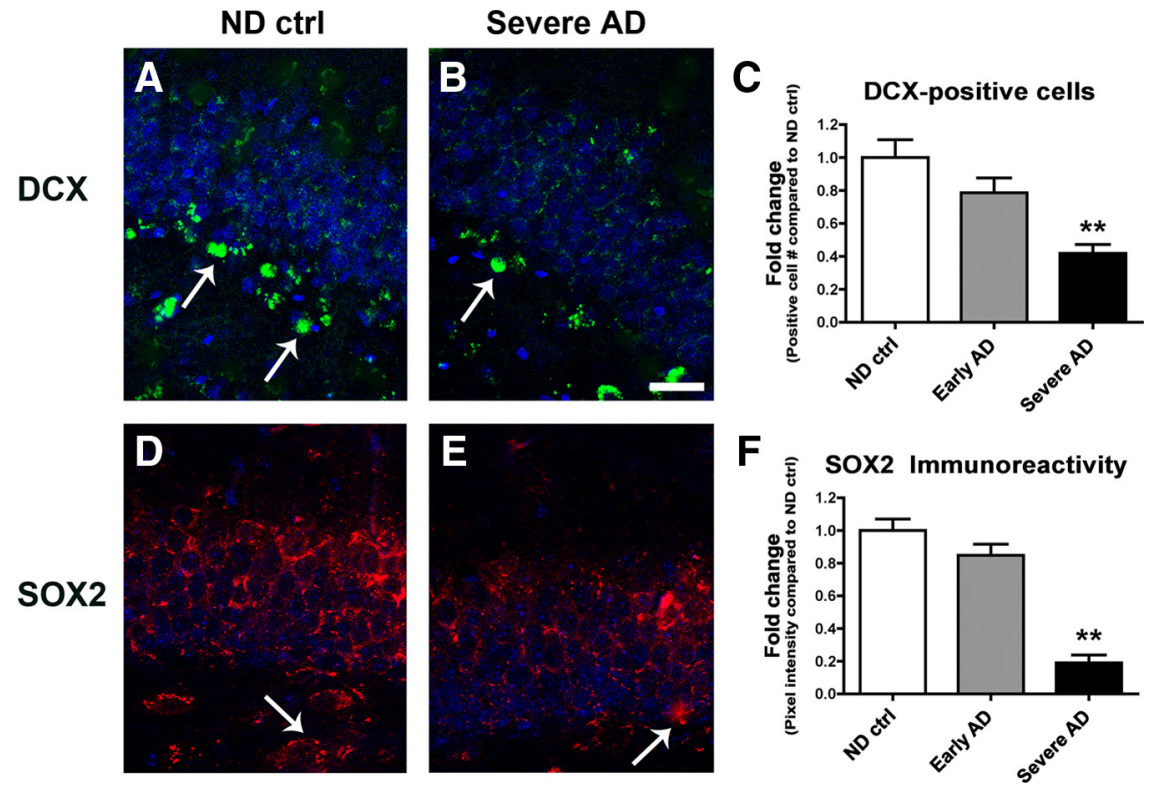

Figure 3. Markers of neurogenesis are reduced in the brains of AD patients. Sections from the hippocampus of age-matched nondemented control (ND ctrl) patients and severe AD cases were immunolabeled with antibodies against DCX detected with a FITC-tagged secondary antibody, or SOX2 detected with Tyramide Red, and imaged by confocal microscopy. All images are from the dentate gyrus, and sections were costained with DAPI (blue) to label cell nuclei. Scale bar, $30 \mu \mathrm{m}$ for all images. $\boldsymbol{A}, \boldsymbol{B}$, Representative immunolabeling of sections from control and $A D$ hippocampus show fewer DCX-positive cells (arrows) in the brains of patients with severe $A D$ compared to nondemented control brains. $C$, Reduced numbers of DCX-positive cells were detected in the dentate gyrus of AD brains compared to controls. $\boldsymbol{D}-\boldsymbol{F}$, Reduced SOX 2 immunoreactivity (arrows, $\boldsymbol{D}, \boldsymbol{E}$ ) in the brains of patients with severe $A D$ compared to nondemented control brains ( $n=5$ nondemented control cases, $n=7$ early $A D$, and $n=7$ severe $A D$ cases analyzed, ${ }^{* *} p<0.01$ compared to nondemented controls by one-way ANOVA with post hoc Dunnett's test).

body preincubated with blocking peptide (supplemental Fig. $1 \mathrm{~F}$, available at www.jneurosci.org as supplemental material) abolished the signal detected in sections from the brain of APP tg mice. Similar patterns of immunoreactivity were observed with both a polyclonal (supplemental Fig. 1G, available at www. jneurosci.org as supplemental material) and monoclonal (supplemental Fig. $1 \mathrm{H}$, available at www.jneurosci.org as supplemental material) antibody against BMP6.

Immunohistochemical analysis with the monoclonal antibody against BMP6 demonstrated increased protein levels of BMP6 in the cytoplasm of DG granular cells in the hippocampus of APP tg mice compared to non-tg controls (Fig. $4 B, C$ ). In APP tg mice, BMP6 immunoreactivity was detected throughout the SGZ and the GCL. Additional analysis with a polyclonal antibody against BMP6 showed a similar pattern of immunoreactivity and increased expression in APP tg mice (Fig. 4D,E). Semiquantitative image analysis of sections immunolabeled with the monoclonal antibody demonstrated a significant increase in BMP6 immunoreactivity in APP tg mouse hippocampus compared to non-tg controls (Fig. 4G). Immunoblot analysis confirmed that BMP6 protein levels were increased in APP tg brains compared to controls (Fig. $4 F, G$ ). In contrast to the human brain samples, in the mouse brain homogenates only a single immunoreactive band was detected around $15-20 \mathrm{kDa}$ corresponding to the mature form of BMP6.

To determine whether BMP6 accumulated surrounding plaques in the hippocampus of APP tg mice similar to the distribution observed in $\mathrm{AD}$ patients, we characterized the patterns of BMP6 immunoreactivity in relation to $\mathrm{A} \beta$-containing plaques in the hippocampus of APP tg mice (Fig. $2 G-L$ ). Similar to the expression patterns observed in the hippocampus of $\mathrm{AD}$ patients, double-immunohistochemical analysis of brain sections from
APP tg mice with a monoclonal antibody against BMP6 and an antibody against $\mathrm{A} \beta$ (6E10) showed a ring-like pattern of BMP6 immunoreactivity surrounding both diffuse (Fig. 2G-I) and mature (Fig. $2 J-L)$ plaques located in the molecular and pyramidal layers of the hippocampus.

To assess whether the alterations in BMP6 expression levels were specific to the mouse hippocampus, or whether changes in BMP6 expression could be detected in other non-neurogenic regions of the brain such as the cortex, immunofluorescent images were obtained from the cortex (layer V) of non-tg and APP tg mouse brain sections immunolabeled with an antibody against BMP6 (supplemental Fig. 2D-F, available at www. jneurosci.org as supplemental material). Similar to the upregulation of BMP6 expression observed in the hippocampus, immunolabeling studies with the monoclonal antibody against BMP6 showed increased BMP6 immunoreactivity in the cortex of APP tg mice compared to non-tg controls (supplemental Fig. 2D-F, available at www.jneurosci.org as supplemental material).

To determine whether markers of neurogenesis were reduced in the hippocampus of APP tg mice as in the AD patients, immunohistochemical analysis was performed with antibodies against BrdU, DCX, and SOX2 (Fig. 5). In animals treated with BrdU, numbers of BrdU-positive cells were significantly reduced in the DG of APP tg mice compared to non-tg controls (Fig. $5 A, B, G)$. Similarly, the numbers of DCX-positive cells (Fig. $5 C, D, G$ ) and SOX2 immunoreactivity (Fig. $5 E-G$ ) were reduced in the DG of APP tg mice compared to non-tg controls. In support of a role for increased BMP6 expression in defective neurogenesis in APP tg mice, double-immunohistochemical analysis of brain sections from APP tg mice showed that BMP6 immunoreactivity was detected in close proximity to, and within, some neurogenic DCX-positive cells in the SGZ (supplemental Fig. $3 D-F$, available at www.jneurosci.org as supplemental material). Together, these results in APP tg mice suggest that abnormal elevation of BMP6 expression in the pathogenesis of AD may play a role in defective adult hippocampal neurogenesis.

\section{A $\beta$ exposure results in increased BMP6 expression in NPCs in vitro}

To further investigate the molecular mechanisms that mediate increased BMP6 expression in AD hippocampus and in APP tg mouse brains, we sought to determine whether BMP6 expression might be augmented as a direct result of exposure to $A \beta$ protein. For this purpose, cultured adult rat hippocampal NPCs were treated with recombinant $\mathrm{A} \beta_{1-42}$ for $24 \mathrm{~h}$, and BMP6 mRNA and protein levels were measured by qRT-PCR and immunoblot, respectively. These studies showed that treatment with $\mathrm{A} \beta_{1-42}$ resulted in a significant $\sim 25 \%$ increase in BMP6 mRNA levels compared to vehicle-treated controls (Fig. 6A) and a concomitant increase in protein levels (Fig. $6 B$ ), suggesting that $A \beta$ may directly modulate BMP6 expression. In the cell lysates of NPCs exposed to exogenous recombinant $\mathrm{A} \beta$, multimeric forms (dimer, 
A
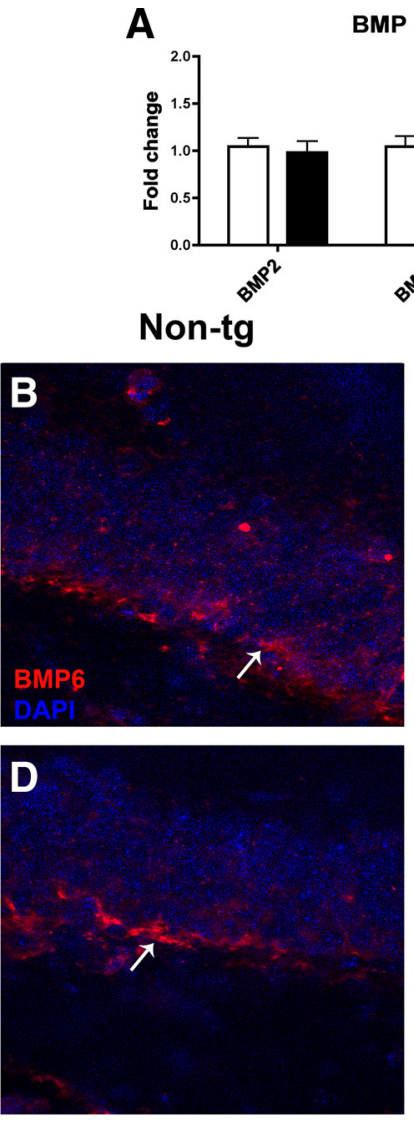

$\mathbf{F}$

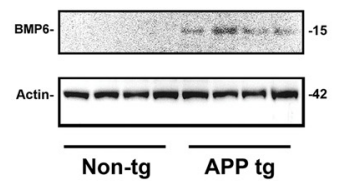

G

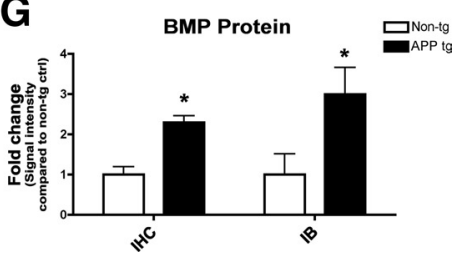

Figure 4. qRT-PCR, immunohistochemical, and immunoblot analyses of BMP levels in the brains of APP tg mice. To screen for changes in BMP expression levels in APP tg mice, mRNA was extracted from the brains of 6-month old non-tg and APP tg mice and prepared for qRT-PCR analysis. $A$, Levels of BMP2, BMP6, and BMP7 mRNA were measured and corrected for $\beta$-actin levels as a control. Of the three BMPs studied, only levels of BMP6 mRNA were significantly increased in the brains of APP tg mice compared to non-tg controls. For immunohistochemical analysis, $\boldsymbol{B}$ and $\boldsymbol{C}$ show representative immunolabeling with a mouse monoclonal antibody against BMP6 (Millipore), and $\boldsymbol{D}$ and $\boldsymbol{E}$ show representative immunolabeling with a rabbit polyclonal antibody against BMP6 (Abgent). All images are from the dentate gyrus, and sections were costained with DAPI (blue) to label cell nuclei. Scale bar, $30 \mu \mathrm{m}$ for all images. $\boldsymbol{B}, \boldsymbol{C}$ Immunohistochemical analysis with a monoclonal antibody against BMP6 showing increased BMP6 immunoreactivity (arrows) in the hippocampus of APP $\operatorname{tg}$ mice $(\boldsymbol{C})$ compared to non-tg controls (B). In APP tg mice, BMP6 immunoreactivity (arrows, $C$ ) was detected throughout the subgranular zone and the granular cell layer. $\boldsymbol{D}, \boldsymbol{E}$, Immunohistochemical analysis with a polyclonal antibody against BMP6 showing similar patterns of immunoreactivity. $\boldsymbol{F}$, Immunoblot analysis showing increased BMP6 protein levels in the brains of APP tg mice compared to non- $\mathrm{tg}$ controls. G, Semiquantitative analysis of levels of BMP6 immunoreactivity by immunohistochemistry (IHC) or immunoblot (IB) with the Millipore antibody confirmed that BMP6 protein levels were increased in the hippocampus of APP $\operatorname{tg}$ mice compared to non- $\operatorname{tg}$ controls $(n=4$ animals per group, ${ }^{*} p<0.05$ compared to non-tg controls by unpaired, two-tailed Student's $t$ test).

trimer) of $A \beta$ were detected after 24 h exposure in addition to the $A \beta$ monomer (Fig. $6 B$ ), suggesting that aggregation of $A \beta$ into small oligomers may play a role in the upregulation of BMP6 expression. These results support the possibility that increased levels of BMP6 may be regulated by the accumulation of $A \beta$ protein in the brains of $\mathrm{AD}$ patients and in APP tg mice.
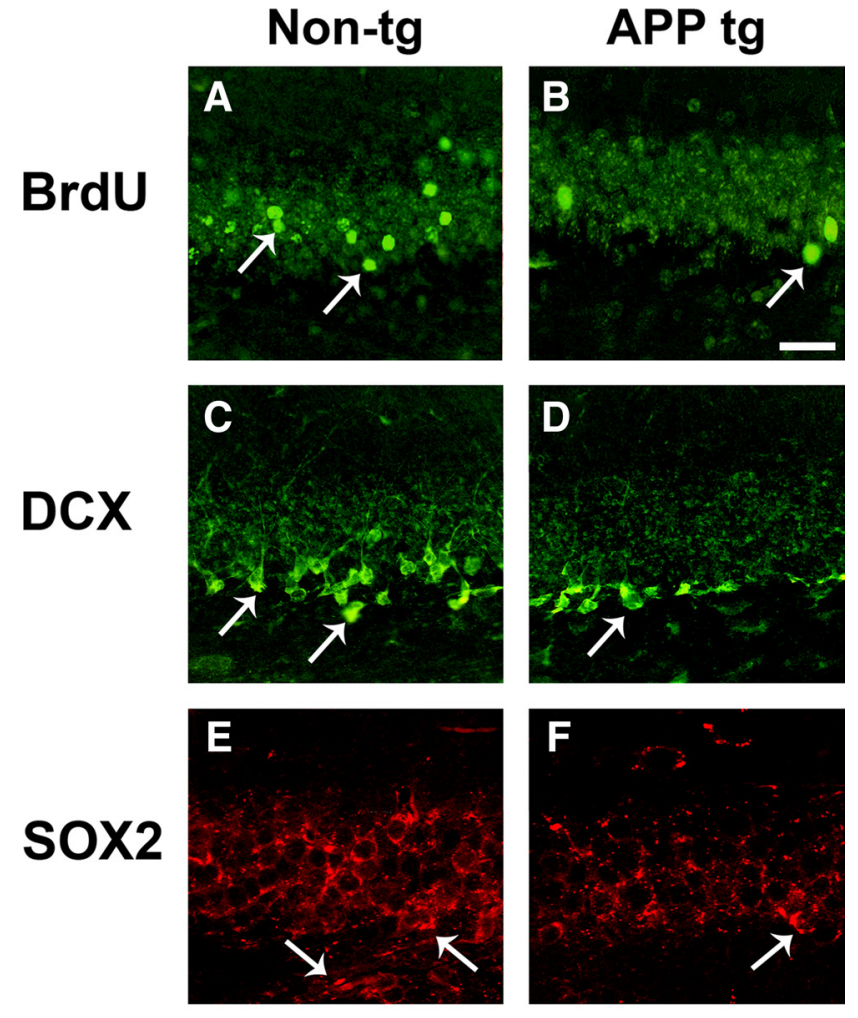

G

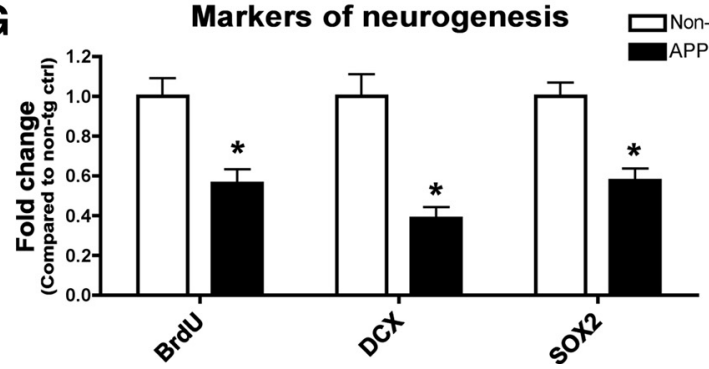

Figure 5. Markers of neurogenesis are reduced in the brains of APP tg mice. Sections from the brains of 6-month old non-tg control and APP tg mice treated with BrdU were immunolabeled with antibodies against BrdU or DCX detected with FITC-tagged secondary antibodies, or SOX2 detected with Tyramide Red and imaged by confocal microscopy. All images are from the hippocampal dentate gyrus. Scale bar, $30 \mu \mathrm{m}$ for all images. $\boldsymbol{A}, \boldsymbol{B}$, Fewer BrdU-positive cells (arrows) were detected in the brains of APP tg mice compared to non-tg controls. C, D, Fewer DCX-positive cells (arrows) were detected in the brains of APP tg mice compared to non-tg controls. DCX-positive cells and processes were observed throughout the granular cell layer in non-tg control brains $(\boldsymbol{C})$, but in APP tg mice DCX-positive cells and processes were less prominent, and were primarily observed only in the subgranular zone ( $\boldsymbol{D}$, arrow). $\boldsymbol{E}, \boldsymbol{F}$, Reduced SOX2 immunoreactivity in the dentate gyrus of APP tg mice compared to non-tg controls. SOX2 immunoreactivity was observed throughout the granular cell layer in the hippocampus of non-tg mice but to a lesser extent in APP tg mice (arrows). G, Semiquantitative analysis showing relative reductions in the numbers of BrdU-positive and DCX-positive cells, and decreased SOX2 immunoreactivity in the hippocampus of APP tg mice compared to non-tg controls $(n=$ 4 animals per group, ${ }^{*} p<0.05$ compared to non-tg controls by unpaired, two-tailed Student's $t$ test).

\section{BMP6 reduces proliferation of NPCs in vitro}

To further investigate the possibility that increased BMP6 levels in the hippocampus in vivo might have an effect on endogenous NPCs, we studied the effects of recombinant BMP6 on cell proliferation and viability in an in vitro cell culture model of adult neurogenesis. For this purpose, cultured adult rat hippocampal NPCs were exposed to 50 or $100 \mathrm{ng} / \mathrm{ml}$ recombinant BMP6 for $4 \mathrm{~d}$ under neuronal differentiation conditions. Live cell imaging demonstrated that treatment with BMP6 at both concentrations 
A

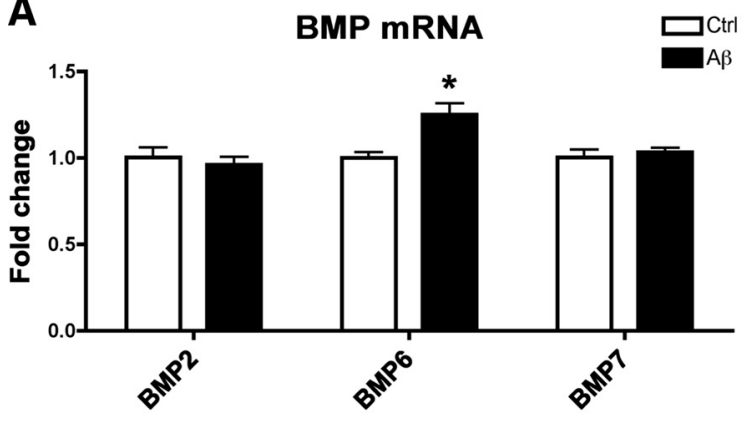

B

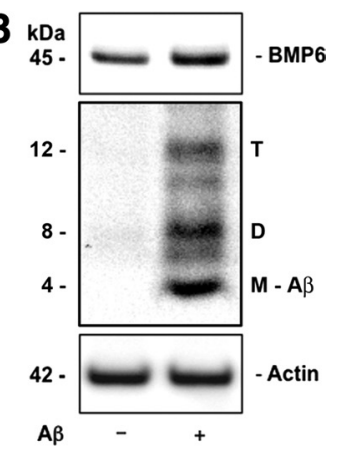

Figure 6. Increased BMP6 expression in cultured NPCs treated with recombinant A $\beta$. Adult rat hippocampal NPCs were cultured for $4 \mathrm{~d}$ under neuronal differentiation conditions, and treated with recombinant $A \beta_{1-42}$ or vehicle control (Ctrl) for the final $24 \mathrm{~h}$ of differentiation. mRNA levels of BMPs were analyzed by qRT-PCR and BMP 6 protein expression was assessed by immunoblot. $A$, mRNA levels of BMP2, BMP6, and BMP7 in A $\beta$-treated NPCs (normalized to levels of the reference gene HPRT). Only BMP6 levels were significantly increased in cultures exposed to $A \beta{ }^{*} p<0.05$ compared to vehicle-treated controls by unpaired two-tailed Student's t test). $\boldsymbol{B}$, Immunoblot analysis of BMP6 protein expression and A $\beta$ accumulation. Increased levels of the BMP6 precursor protein were observed in $A \beta$-treated cell cultures. Multiple $A \beta$ species ( $M$, monomer; $D$, dimer; $T$, trimer) were detected in the cell lysates of cultures treated with $A \beta$. Actin was used as a loading control.

D4 Ctrl

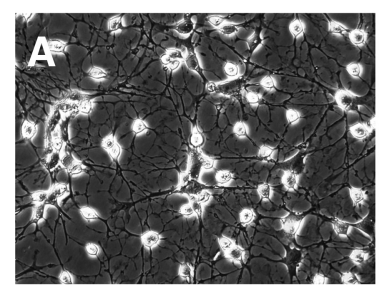

D BrdU

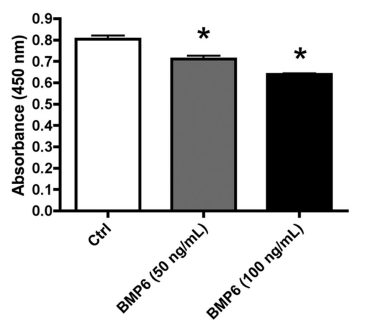

BMP6 (50ng/mL)

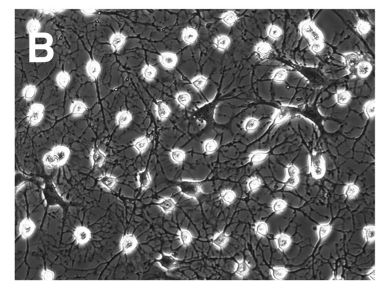

E

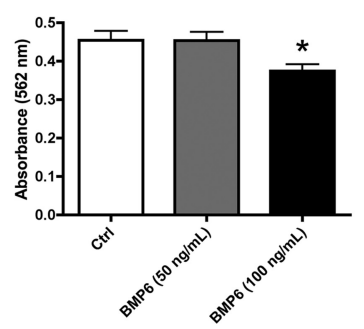

BMP6 (100ng/mL)

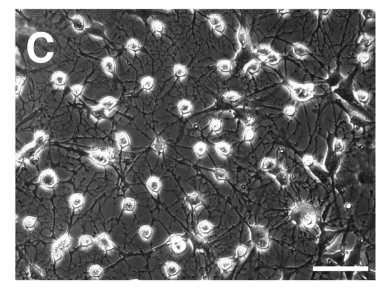

$\mathbf{F}$

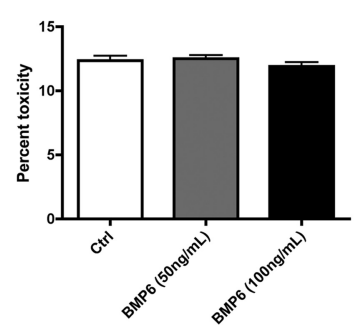

Figure 7. Cell morphology and proliferation, viability, and toxicity studies in cultured NPCs treated with BMP6. Adult rat hippocampal NPCs were cultured for $4 \mathrm{~d}$ under neuronal differentiation conditions in the presence of recombinant human BMP6 or vehicle control (Ctrl), and analyzed by proliferation (BrdU uptake), viability (MTT), and toxicity (LDH release) assays. A-C, Phasecontrast images showing the morphology of live cell cultures after $4 \mathrm{~d}$ of differentiation and treatment with BMP6. Scale bar, 30 $\mu \mathrm{m}$ for all images. D, BMP6 exposure resulted in a reduction of cell proliferation compared to vehicle-treated controls, as shown by reduced BrdU uptake. $E$, Mitochondrial activity was reduced only in cultures treated with the higher $(100 \mathrm{ng} / \mathrm{ml})$ dose of BMP6, as shown by MTT assay. $\boldsymbol{F}$, BMP6 treatment did not significantly affect cell toxicity, as shown by LDH assay $\left({ }^{*} p<0.05\right.$ compared to vehicle-treated controls by one-way ANOVA with post hoc Dunnett's test).

resulted in cultures with no noticeable morphological differences compared to controls (Fig. 7A-C). Treatment with BMP6 resulted in a significant and dose-dependent reduction in cell proliferation as measured by BrdU uptake (Fig. 7D), and a decrease in overall mitochondrial activity as measured by MTT assay only with the higher dose of BMP6 (100 ng/ml) (Fig. 7E). This suggests that the BMP6 treatment might decrease cell numbers by reducing proliferation or because of a toxic effect. To test the latter possibility, measurements of levels of LDH release were taken and showed no significant differences (Fig. $7 F$ ). Together, these results support the possibility that BMP6 directly interferes with neurogenesis by modulating NPC proliferation.

\section{Discussion}

The present study showed that levels of BMP6 were increased approximately twofold to fourfold in the hippocampus of patients with AD and in APP tg mice compared to controls; however, no significant differences were detected in the mRNA levels of two other BMPs, BMP2 and BMP7. A striking pattern of BMP6 distribution was also observed in plaquecontaining regions of the hippocampus in both AD patients and APP tg mice, where $\mathrm{A} \beta$-containing plaques were surrounded by a ring-like pattern of BMP6 immunoreactivity. Since BMP6 is a secreted protein, and its primary reported role in the brain is in regulating developmental neurogenesis, it is possible that abnormally elevated levels of this protein in $\mathrm{AD}$ might affect adult neurogenesis in the hippocampus.

It is important to note that neurogenesis persists in the aged brain; however, its rate declines with increasing age, as revealed by previous studies in rodents (Kuhn et al., 1996; Kempermann et al., 1998), nonhuman primates (Gould et al., 1999), and humans (Cameron and McKay, 1999). Despite this natural decline with age, previous studies have shown that the adult brain remains responsive to therapeutic interventions that enhance neurogenesis (Jin et al., 2003; Wise, 2003). Understanding the molecular mechanisms involved in $\mathrm{AD}$-related alterations in neurogenesis might help guide the development of new therapies in this direction. Interestingly, paralleling the decline in both the pool of NPCs and their proliferative potential in $\mathrm{AD}$, the levels of various neurotrophic factors, including BDNF (brainderived neurotrophic factor), SCF (stem cell factor), and neurosteroids, among others, are dysregulated in $\mathrm{AD}$ and $\mathrm{FAD}$-linked models (Weill-Engerer et al., 2002; Laske et al., 2008) (for review, see Schindowski et al., 2008). These studies suggest that the neurogenic niche is dramatically altered in the pathogenesis of $\mathrm{AD}$, and other growth factors may be aberrantly expressed as well.

In support of the possibility that alterations in BMP6 expression in AD may dysregulate adult neurogenesis, we showed that markers of neurogenesis were altered in the hippocampus of $\mathrm{AD}$ patients and $\mathrm{APP}$ tg mice compared to controls. Furthermore, in an in vitro model of adult hippocampal neurogenesis, we showed that exposure to $A \beta$ protein upregulated BMP6 expression levels, and treatment with recombinant BMP6 reduced NPC proliferation.

The members of the BMP family of growth factors belong to various subclasses distinguished by amino acid sequence similarity, and $\sim 20$ unique BMP ligands have been identified to date (Wordinger and Clark, 2007). Although the primary function of many of the BMPs is in osteogenesis, the class 1 (BMP2/4) and 
class 2 (BMP5/6/7/8) families have been previously implicated in CNS development and disease. For example, BMPs are important regulators of embryonic neurogenesis (Mehler et al., 1997) and during embryonic brain development, the inhibition of these growth factors promotes neurogenesis (Nakashima and Taga, 2002). The canonical role of BMPs in the developing brain is to promote glial differentiation via Smad signaling (Mehler et al., 1997), and previous studies have shown that BMP2 induces astrocyte differentiation in mouse embryonic neuroepithelial cell cultures (Gross et al., 1996; Fukuda and Taga, 2005; Fukuda et al., 2007). BMPs have been implicated in embryonic (Mehler et al., 1997) and adult (Colak et al., 2008) neurogenesis, and BMP activity has been shown to regulate synaptic plasticity in the adult hippocampus (Sun et al., 2007); however, the role of BMPs in neurodegenerative disorders is less clear.

In support of a role for $\mathrm{BMPs}$ in $\mathrm{AD}$, two recent publications have shown that BMP4 levels are increased in the brains of an animal model of AD (Li et al., 2008b; Tang et al., 2009). High levels of BMP4 were associated with reduced neurogenesis in the DG of mice expressing mutant forms of APP and presenilin-1 (PS1) (Li et al., 2008b; Tang et al., 2009). Increased BMP4 expression was accompanied by reduced expression of the BMP inhibitor Noggin (Tang et al., 2009); however, the precise mechanisms through which BMP4 levels are increased during the pathogenesis of $\mathrm{AD}$ remain unclear.

In contrast to the defective neurogenesis observed in association with elevated levels of BMPs in AD (Li et al., 2008b; Tang et al., 2009; present study), another related protein, BMP7 (osteogenic protein1), has been proposed to have neuroregenerative capacity in acute CNS injury. BMP7 has been shown to be neuroprotective against nigrostriatal toxicity in a 6-hydroxydopamine rat model of Parkinson's disease (Harvey et al., 2004) and is under investigation as a potential therapy in acute CNS injuries such as stroke (Kawabata et al., 1998; Ren et al., 2000; Chou et al., 2006). Interestingly, both BMP7 and its receptors are upregulated after acute CNS injury or stroke (Lewén et al., 1997; Charytoniuk et al., 2000; Chang et al., 2003; Harvey et al., 2005), suggesting that the increased expression of BMP7 after injury might represent a protective response. Another recent study showed that BMP6, but not BMP7, is protective against apoptosis triggered by acute potassium withdrawal in cerebellar granule neurons (Barneda-Zahonero et al., 2009). Together, these results suggest that it is possible that acute upregulation of BMP expression may be a compensatory response that is protective in the short term, while chronic upregulation of BMPs in the AD mouse models may result in defective neurogenesis possibly via modification of expression or function of receptors and downstream signaling pathways. Moreover, it may be important to exercise caution in long-term therapeutic studies using BMPs in acute CNS injury, as it is possible that elevated levels of these factors may have negative side effects on adult neurogenesis.

Since our results show that BMP6 is specifically increased in a mouse model overexpressing APP, it is possible that APP or APP products such as $\mathrm{A} \beta$ might play a role in producing the abnormal levels of BMP6. The precise transcriptional regulators involved remain to be determined; however, the present data show that treatment with exogenous $\mathrm{A} \beta$ upregulates expression of BMP6, and it is possible that $\mathrm{A} \beta$ may stimulate signaling pathways that activate transcription of BMP6. In the in vitro $\mathrm{A} \beta$ preparations, multiple species including monomers, dimers, and trimers were detected after $24 \mathrm{~h}$ of exposure. This is consistent with the predominant $\mathrm{A} \beta$ species detected in human $\mathrm{AD}$ and $\mathrm{APP}$ tg mouse brains, where most recent studies suggest that relatively small oligomers are responsible for the synaptotoxic effects of $A \beta$
(Lacor et al., 2004). In this context, it is possible that these smaller oligomeric species may also be responsible for alterations in neurogenesis; however, future studies will be necessary to elucidate the precise species that modulate BMP6 expression and neurogenesis. Previous studies have shown that BMP6 production is transcriptionally regulated by hormones such as estrogen (Zhang et al., 2005) and glucocorticoids (Liu et al., 2004). Although increased glucocorticoid production has been identified as an early feature in $\mathrm{AD}$ pathogenesis that specifically targets the hippocampus (Dhikav and Anand, 2007), it is unknown whether A $\beta$ or its oligomeric aggregates might interact with glucocorticoid receptors, and future studies will be necessary to elucidate the precise transcription factors involved in $\mathrm{A} \beta$-mediated regulation of BMP6 expression.

In addition to uncovering a potential link between elevated levels of BMP6 and reduced neurogenesis in AD brains and APP tg mice, the present study suggests that the increased levels of BMP6 observed in the hippocampus of AD patients and APP tg mice might directly impair the proliferation of hippocampal NPCs. In this context, we showed that treatment with recombinant BMP6 in an in vitro model of adult neurogenesis reduced proliferation without an overt toxic effect; however, understanding the precise downstream pathways that impair NPC proliferation will require further investigation. We propose that normalization of BMP expression in models of $\mathrm{AD}$ may present a novel therapeutic approach for protecting against the neurogenic alterations in $\mathrm{AD}$.

Together, the data presented here suggest that increased levels of BMP6 in AD might directly interfere with the process of adult neurogenesis in the hippocampus. We also demonstrated that BMP6 protein levels were increased in the non-neurogenic cortex, suggesting that the observed changes in BMP6 expression may occur in multiple brain regions. This could be specific to regions that are more severely affected by $\mathrm{AD}$-related pathological alterations, or it could be a global effect. For the present study, we focused on the effects of increased BMP6 expression on neurogenic cells because of the known role of BMP6 in embryonic neurogenesis; however, future studies will be necessary to elucidate the impact of increased BMP6 expression on mature neuronal circuitries in non-neurogenic brain regions.

In both neurogenic and non-neurogenic regions of the brain, APP products such as A $\beta$ may be responsible for increased BMP production, possibly via receptor-mediated transcriptional regulation. Moreover, BMPs might have a neuroprotective effect during the acute phase of CNS injury, but in chronic neurodegenerative processes such as AD they may contribute to pathophysiology. Further investigation will be necessary to elucidate the precise mechanisms involved in regulating BMP expression in AD and the effects on NPCs in the adult hippocampus, and in future studies BMPs may be important targets for therapeutic intervention to rescue the neurogenic deficits associated with the pathogenesis of $\mathrm{AD}$.

\section{References}

Arndt S, Maegdefrau U, Dorn C, Schardt K, Hellerbrand C, Bosserhoff AK (2010) Iron-induced expression of bone morphogenic protein 6 in intestinal cells is the main regulator of hepatic hepcidin expression in vivo. Gastroenterology 138:372-382.

Barneda-Zahonero B, Miñano-Molina A, Badiola N, Fadó R, Xifró X, Saura CA, Rodríguez-Alvarez J (2009) Bone morphogenetic protein-6 promotes cerebellar granule neurons survival by activation of the MEK/ERK/ CREB pathway. Mol Biol Cell 20:5051-5063.

Boekhoorn K, Joels M, Lucassen PJ (2006) Increased proliferation reflects 
glial and vascular-associated changes, but not neurogenesis in the presenile Alzheimer hippocampus. Neurobiol Dis 24:1-14.

Cameron HA, McKay RD (1999) Restoring production of hippocampal neurons in old age. Nat Neurosci 2:894-897.

Chang CF, Lin SZ, Chiang YH, Morales M, Chou J, Lein P, Chen HL, Hoffer BJ, Wang Y (2003) Intravenous administration of bone morphogenetic protein-7 after ischemia improves motor function in stroke rats. Stroke 34:558-564.

Charytoniuk DA, Traiffort E, Pinard E, Issertial O, Seylaz J, Ruat M (2000) Distribution of bone morphogenetic protein and bone morphogenetic protein receptor transcripts in the rodent nervous system and upregulation of bone morphogenetic protein receptor type II in hippocampal dentate gyrus in a rat model of global cerebral ischemia. Neuroscience 100:33-43.

Chou J, Harvey BK, Chang CF, Shen H, Morales M, Wang Y (2006) Neuroregenerative effects of BMP7 after stroke in rats. J Neurol Sci 240:21-29.

Colak D, Mori T, Brill MS, Pfeifer A, Falk S, Deng C, Monteiro R, Mummery C, Sommer L, Götz M (2008) Adult neurogenesis requires Smad4mediated bone morphogenic protein signaling in stem cells. J Neurosci 28:434-446.

Cole G, Dobkins KR, Hansen LA, Terry RD, Saitoh T (1988) Decreased levels of protein kinase C in Alzheimer brain. Brain Res 452:165-174.

Crews L, Rockenstein E, Masliah E (2010) APP transgenic modeling of Alzheimer's disease: mechanisms of neurodegeneration and aberrant neurogenesis. Brain Struct Funct 214:111-126.

Demars M, Hu YS, Gadadhar A, Lazarov O (2010) Impaired neurogenesis is an early event in the etiology of familial Alzheimer's disease in transgenic mice. J Neurosci Res 88:2103-2117.

Dhikav V, Anand KS (2007) Glucocorticoids may initiate Alzheimer's disease: a potential therapeutic role for mifepristone (RU-486). Med Hypotheses 68:1088-1092.

Diez del Corral R, Storey KG (2001) Markers in vertebrate neurogenesis. Nat Rev Neurosci 2:835-839.

Dong H, Goico B, Martin M, Csernansky CA, Bertchume A, Csernansky JG (2004) Modulation of hippocampal cell proliferation, memory, and amyloid plaque deposition in APPsw (Tg2576) mutant mice by isolation stress. Neuroscience 127:601-609.

Donovan MH, Yazdani U, Norris RD, Games D, German DC, Eisch AJ (2006) Decreased adult hippocampal neurogenesis in the PDAPP mouse model of Alzheimer's disease. J Comp Neurol 495:70-83.

Fukuda S, Taga T (2005) Cell fate determination regulated by a transcriptional signal network in the developing mouse brain. Anat Sci Int $80: 12-18$.

Fukuda S, Abematsu M, Mori H, Yanagisawa M, Kagawa T, Nakashima K, Yoshimura A, Taga T (2007) Potentiation of astrogliogenesis by STAT3mediated activation of bone morphogenetic protein-Smad signaling in neural stem cells. Mol Cell Biol 27:4931-4937.

Gage FH, Kempermann G, Palmer TD, Peterson DA, Ray J (1998) Multipotent progenitor cells in the adult dentate gyrus. J Neurobiol 36:249-266.

Gould E, Reeves AJ, Fallah M, Tanapat P, Gross CG, Fuchs E (1999) Hippocampal neurogenesis in adult Old World primates. Proc Natl Acad Sci U S A 96:5263-5267.

Gross RE, Mehler MF, Mabie PC, Zang Z, Santschi L, Kessler JA (1996) Bone morphogenetic proteins promote astroglial lineage commitment by mammalian subventricular zone progenitor cells. Neuron 17:595-606.

Gundersen HJ, Bagger P, Bendtsen TF, Evans SM, Korbo L, Marcussen N, Møller A, Nielsen K, Nyengaard JR, Pakkenberg B, Sørensen FB, Vesterby A, West MJ (1988) The new stereological tools: disector, fractionator, nucleator and point sampled intercepts and their use in pathological research and diagnosis. Apmis 96:857-881.

Harvey BK, Mark A, Chou J, Chen GJ, Hoffer BJ, Wang Y (2004) Neurotrophic effects of bone morphogenetic protein-7 in a rat model of Parkinson's disease. Brain Res 1022:88-95.

Harvey BK, Hoffer BJ, Wang Y (2005) Stroke and TGF-beta proteins: glial cell line-derived neurotrophic factor and bone morphogenetic protein. Pharmacol Ther 105:113-125.

Haughey NJ, Liu D, Nath A, Borchard AC, Mattson MP (2002a) Disruption of neurogenesis in the subventricular zone of adult mice, and in human cortical neuronal precursor cells in culture, by amyloid beta-peptide: implications for the pathogenesis of Alzheimer's disease. Neuromolecular Med 1:125-135.

Haughey NJ, Nath A, Chan SL, Borchard AC, Rao MS, Mattson MP (2002b)
Disruption of neurogenesis by amyloid beta-peptide, and perturbed neural progenitor cell homeostasis, in models of Alzheimer's disease. J Neurochem 83:1509-1524.

Jin K, Sun Y, Xie L, Batteur S, Mao XO, Smelick C, Logvinova A, Greenberg DA (2003) Neurogenesis and aging: FGF-2 and HB-EGF restore neurogenesis in hippocampus and subventricular zone of aged mice. Aging Cell 2:175-183.

Jin K, Galvan V, Xie L, Mao XO, Gorostiza OF, Bredesen DE, Greenberg DA (2004a) Enhanced neurogenesis in Alzheimer's disease transgenic (PDGF-APPSw, Ind) mice. Proc Natl Acad Sci U S A 101:13363-13367.

Jin K, Peel AL, Mao XO, Xie L, Cottrell BA, Henshall DC, Greenberg DA (2004b) Increased hippocampal neurogenesis in Alzheimer's disease. Proc Natl Acad Sci U S A 101:343-347.

Kawabata M, Imamura T, Miyazono K (1998) Signal transduction by bone morphogenetic proteins. Cytokine Growth Factor Rev 9:49-61.

Kempermann G, Kuhn HG, Gage FH (1998) Experience-induced neurogenesis in the senescent dentate gyrus. J Neurosci 18:3206-3212.

Kuhn HG, Dickinson-Anson H, Gage FH (1996) Neurogenesis in the dentate gyrus of the adult rat: age-related decrease of neuronal progenitor proliferation. J Neurosci 16:2027-2033.

Lacor PN, Buniel MC, Chang L, Fernandez SJ, Gong Y, Viola KL, Lambert MP, Velasco PT, Bigio EH, Finch CE, Krafft GA, Klein WL (2004) Synaptic targeting by Alzheimer's-related amyloid beta oligomers. J Neurosci 24:10191-10200.

Laske C, Stellos K, Stransky E, Seizer P, Akcay O, Eschweiler GW, Leyhe T, Gawaz M (2008) Decreased plasma and cerebrospinal fluid levels of stem cell factor in patients with early Alzheimer's disease. J Alzheimers Dis 15:451-460.

Lazarov O, Marr RA (2010) Neurogenesis and Alzheimer's disease: at the crossroads. Exp Neurol 223:267-281.

Lewén A, Söderström S, Hillered L, Ebendal T (1997) Expression of serine/ threonine kinase receptors in traumatic brain injury. Neuroreport 8:475-479.

Li B, Yamamori H, Tatebayashi Y, Shafit-Zagardo B, Tanimukai H, Chen S, Iqbal K, Grundke-Iqbal I (2008a) Failure of neuronal maturation in Alzheimer disease dentate gyrus. J Neuropathol Exp Neurol 67:78-84.

Li D, Tang J, Xu H, Fan X, Bai Y, Yang L (2008b) Decreased hippocampal cell proliferation correlates with increased expression of BMP4 in the APPswe/PS1DeltaE9 mouse model of Alzheimer's disease. Hippocampus 18:692-698.

Liu Y, Titus L, Barghouthi M, Viggeswarapu M, Hair G, Boden SD (2004) Glucocorticoid regulation of human BMP-6 transcription. Bone 35:673-681.

Masliah E, Mallory M, Alford M, DeTeresa R, Iwai A, Saitoh T (1997) Molecular mechanisms of synaptic disconnection in Alzheimer's disease. In: Connections, cognition and Alzheimer's disease (Hyman B, Duyckaerts C, Christen Y, eds), pp 121-140. Berlin: Springer.

Masliah E, Rockenstein E, Veinbergs I, Mallory M, Hashimoto M, Takeda A, Sagara Y, Sisk A, Mucke L (2000) Dopaminergic loss and inclusion body formation in alpha-synuclein mice: implications for neurodegenerative disorders. Science 287:1265-1269.

Mehler MF, Mabie PC, Zhang D, Kessler JA (1997) Bone morphogenetic proteins in the nervous system. Trends Neurosci 20:309-317.

Nakashima K, Taga T (2002) Mechanisms underlying cytokine-mediated cell-fate regulation in the nervous system. Mol Neurobiol 25:233-244.

Pernas-Alonso R, Morelli F, di Porzio U, Perrone-Capano C (1999) Multiplex semi-quantitative reverse transcriptase-polymerase chain reaction of low abundance neuronal mRNAs. Brain Res Brain Res Protoc 4:395-406.

Ray J, Gage FH (2006) Differential properties of adult rat and mouse brainderived neural stem/progenitor cells. Mol Cell Neurosci 31:560-573.

Ren J, Kaplan PL, Charette MF, Speller H, Finklestein SP (2000) Time window of intracisternal osteogenic protein-1 in enhancing functional recovery after stroke. Neuropharmacology 39:860-865.

Rockenstein E, Mallory M, Mante M, Sisk A, Masliaha E (2001) Early formation of mature amyloid-b proteins deposits in a mutant APP transgenic model depends on levels of Ab1-42. J Neurosci Res 66:573-582.

Rockenstein E, Mallory M, Mante M, Alford M, Windisch M, Moessler H, Masliah E (2002) Effects of Cerebrolysin on amyloid-beta deposition in a transgenic model of Alzheimer's disease. J Neural Transm Suppl 327-336.

Rockenstein E, Adame A, Mante M, Moessler H, Windisch M, Masliah E (2003) The neuroprotective effects of Cerebrolysin ${ }^{\mathrm{TM}}$ in a transgenic 
model of Alzheimer's disease are associated with improved behavioral performance. J Neural Transm 110:1313-1327.

Rockenstein E, Mante M, Adame A, Crews L, Moessler H, Masliah E (2007) Effects of Cerebrolysin ${ }^{\mathrm{TM}}$ on neurogenesis in an APP transgenic model of Alzheimer's disease. Acta Neuropathol 113:265-275.

Rowe WB, Blalock EM, Chen KC, Kadish I, Wang D, Barrett JE, Thibault O, Porter NM, Rose GM, Landfield PW (2007) Hippocampal expression analyses reveal selective association of immediate-early, neuroenergetic, and myelinogenic pathways with cognitive impairment in aged rats. J Neurosci 27:3098-3110.

Saremba S, Nickel J, Seher A, Kotzsch A, Sebald W, Mueller TD (2008) Type I receptor binding of bone morphogenetic protein 6 is dependent on $\mathrm{N}$-glycosylation of the ligand. FEBS J 275:172-183.

Schindowski K, Belarbi K, Buée L (2008) Neurotrophic factors in Alzheimer's disease: role of axonal transport. Genes Brain Behav 7 [Suppl 1]:43-56.

Selkoe DJ (1989) Amyloid $\beta$ protein precursor and the pathogenesis of Alzheimer's disease. Cell 58:611-612.

Selkoe DJ (1999) Translating cell biology into therapeutic advances in Alzheimer's disease. Nature 399:A23-A31.

Sun M, Thomas MJ, Herder R, Bofenkamp ML, Selleck SB, O'Connor MB (2007) Presynaptic contributions of chordin to hippocampal plasticity and spatial learning. J Neurosci 27:7740-7750.

Tang J, Song M, Wang Y, Fan X, Xu H, Bai Y (2009) Noggin and BMP4 co-modulate adult hippocampal neurogenesis in the APP(swe)/ PS1(DeltaE9) transgenic mouse model of Alzheimer's disease. Biochem Biophys Res Commun 385:341-345.
Tatebayashi Y, Lee MH, Li L, Iqbal K, Grundke-Iqbal I (2003) The dentate gyrus neurogenesis: a therapeutic target for Alzheimer's disease. Acta Neuropathol 105:225-232.

Terry RD, Peck A, DeTeresa R, Schechter R, Horoupian DS (1981) Some morphometric aspects of the brain in senile dementia of the Alzheimer type. Ann Neurol 10:184-192.

Terry RD, Masliah E, Hansen LA (1994) Structural basis of the cognitive alterations in Alzheimer disease. In: Alzheimer disease (Terry RD, Katzman R, Bick KL, eds), pp 179-196. New York: Raven.

Verwer RW, Bick KL, Sluiter AA, Balesar RA, Baayen JC, Noske DP, Dirven CM, Wouda J, van Dam AM, Lucassen PJ, Swaab DF (2007) Mature astrocytes in the adult human neocortex express the early neuronal marker doublecortin. Brain 130:3321-3335.

Weill-Engerer S, David JP, Sazdovitch V, Liere P, Eychenne B, Pianos A, Schumacher M, Delacourte A, Baulieu EE, Akwa Y (2002) Neurosteroid quantification in human brain regions: comparison between Alzheimer's and nondemented patients. J Clin Endocrinol Metab 87:5138-5143.

Williams RW, Rakic P (1988) Three-dimensional counting: an accurate and direct method to estimate numbers of cells in sectioned material. J Comp Neurol 278:344-352.

Wise PM (2003) Creating new neurons in old brains. Sci Aging Knowledge Environ 2003:PE13.

Wordinger RJ, Clark AF (2007) Bone morphogenetic proteins and their receptors in the eye. Exp Biol Med (Maywood) 232:979-992.

Zhang M, Yan JD, Zhang L, Wang Q, Lü SJ, Zhang J, Zhu TH (2005) Activation of bone morphogenetic protein- 6 gene transcription in MCF-7 cells by estrogen. Chin Med J (Engl) 118:1629-1636. 